\title{
The Relation Between Residential Self-Selection and Urban Mobility in Middle Eastern Cities: the Case of Alexandria, Egypt
}

\author{
Houshmand Masoumi ${ }^{1,2}$ (D) Mohamed R. Ibrahim $^{3}$ - Atif Bilal Aslam ${ }^{4}$
}

Accepted: 15 December 2020/ Published online: 7 January 2021

(C) The Author(s) 2021

\begin{abstract}
The present paper attempts to fill a part of the gap in the studies on residential location choices and their relations to urban mobility, socio-economics, and the built environment by presenting the results of a study on Alexandria, Egypt, by analysing the results of a survey in eight neighbourhoods undertaken in 2015. Four questions were answered in this study: (i) "How are the main drivers behind residential location choices in Alexandria connected to various socio-demographic groups or people with different availability to urban and built environments?", (ii) "How are the main residential selfselections in Alexandria associated with one another and which are the most important?", (iii) "How are the housing location-related decisions of Egyptians similar to or different from international decisions?", and (iv) "How can planners and decisionmakers use the knowledge produced by this study for urban planning and housing in Egypt?". Library work and the results of a $X^{2}$ test of independence show that availability of transportation modes, nice neighbourhoods, and affordability are the strongest motives behind decisions. However, socio-economic factors are generally stronger than urban mobility and spatial issues. These findings are partly different from those of high-income countries.
\end{abstract}

Keywords Residential self-selection · Residential location choice · Urban transportation · Alexandria

\section{Introduction}

The topic of residential self-selection and location choices has been widely studied within the context of the developed world. However, it is still a topic of rigorous and deep investigation as the evidence from the high-income countries suggests that the

Houshmand Masoumi

masoumi@ztg.tu-berlin.de

Extended author information available on the last page of the article 
association of housing location choices and the travel attitude of the residents is not entirely clear yet. But when it comes to discussing the results from the developing world, it is found that the topic has still been under-researched. Keeping the dearth of similar studies emerging from the developing world, it is difficult to point out the similarities and differences of the self-behaviour concerning residential location choices from these two different parts of the world.

The topic of residential self-selection has started gaining attention in the developing world, and the studies within the context of low-income countries are also being surfaced; however, their volume in the overall literature is very less. Apart from a very few studies on the topic emerging from the Middle East and North Africa (MENA) region, it is difficult to find similar studies offering insights for better conceptual understanding of the topic. The studies from the high-income countries mainly report on the factors determining the peoples' housing choices as proximity to social contacts and networks; , school quality (Guidon et al. 2019); mobility, travel attitude, and built environment (Zang et al. 2019; Heinen et al. 2018; Ettema and Nieuwenhuis 2017; Scheiner 2014; Boone-Heinonen et al. 2010; Cao et al. 2009; Cao 2014; Næss 2009); accessibility to jobs and services (Baraklianos et al. 2018; Hu and Wang 2019); , and affordability and neighbourhood quality, including school quality (Lee and Waddell 2010; Bayoh et al. 2006). Generally, such studies reporting on the factors of housing location choices in the Middle East and North Africa (MENA) region are very limited. To fill the literature gap, Ibrahim (2017b) conducted a study on the topic and, while presenting the findings descriptively, found out the availability of transportation modes as the chief factor in deciding the residential location choices in Alexandria, Egypt. In this study, the factors of neighbourhood quality, affordability, and proximity to social contacts and accessibility for housing location choices were found less significant. The descriptive findings of this study show less similarity and more differences with the results of the studies emerging from the high-income countries. However, the results from other parts of the developing world show more conformity with these findings. Aslam et al. (2019) conducted a study on the similar topic in a small town (Hafizabad) of Pakistan and found the availability of utility services and affordability the most important factors in the decision-making process of the residential location choices. Masoumi (2013) also found socio-economic factors as the key determinants of residential self-selection in the Iranian city of Tehran. Other studies on the topic within the context of the developing world have also reported more or less similar findings by concluding socio-economic factors and neighbourhood conditions (De and Vupru 2017; Ubani et al. 2017; Poku-Boansi and Adarkwa 2016), spatial factors (Digambar et al. 2010), accessibility and travel attitudes (Cao and Yang 2017; Wang and Lin 2014; Jiao and Harata 2007), security and affordability (Ubani et al. 2017), religious factors (Sinniah et al. 2016), and comfort and convenience (Wang et al. 2016), as the main factors for housing location choices. These literature findings suggest the importance of contextual setting for addressing variations in the results across the globe and provide a rationale of having a deep inquiry into the subject for a better understanding.

On the other hand, integrated transport planning has been seen as a response to address many urban issues related to mobility and travel. This topic has widely been researched from various associated dimensions, across the developed and developing world. However, the effects of such transport planning measures on the residential location choices have not been entirely clear (Cao et al. 2009). Nevertheless, integrating 
transport planning decisions with residential location choices has been suggested for sustainable urban development (Acheampong 2018). The process of residential location choices does not contest integrated land use and transportation (ILUT) strategies rather it finds complementarities with ILUT strategies (Bruns and Matthes 2019), and thus, residential location choices need to be integrated with transport and land use models (Ho et al. 2017).

The past studies, on the topic of residential location choices, employed a variety of theoretical frameworks and methodologies to draw the results across developed and developing countries. Such studies range from qualitative inquiries based on literature reviews (such as Van der Vlist et al. 2002) or in-depth interviews (such as Bruns and Matthes 2019) to quantitative analyses using national census databases (such as Zondag and Pieters 2005), city or regional level census databases (such as Ahmad 1993; Sener et al. 2011; Heldt et al. 2016), primary data collection (Fatmi et al. 2017; Frank et al. 2007; Yu et al. 2017), or data generated by simulators (such as de Palma et al. 2005). The techniques used for quantitative data analysis for such studies range from simple descriptive analysis (such as Aslam et al. 2019, Ibrahim 2017b) to more advanced inferential analyses, mainly employing statistical modelling (such as De Vos and Witlox 2016; Humphreys and Ahern 2019). The studies which conducted field surveys for data collection, neighbourhood, or residential districts have remained their main unit of analysis for drawing the findings (such as Cao et al. 2006; Handy and Clifton 2001). The main considerations while selecting different study neighbourhoods in such studies were similarities and differences in the socio-economic characteristics and the built up form.

The main objective of this study is to highlight the factors which determine the housing location choices of the people in a less studied context of the developing world, particularly North Africa. It also explores the importance level of the various factors grouped as socio-economic, transportation, and spatial characteristics in deciding the residential locations. It is further aimed to disclose the similarities and differences of the decisions made concerning residential location choices by the residents of developed and developing countries. Finally, it is intended to inform the relevant policy organizations guiding them to integrate the findings of this study in the policy formulation.

The present paper is original and novel because similar empirical studies using statistical analysis based on primary data have been rarely conducted on the North Africa and also the Middle East regions. Egypt is considered a country in both regions, which accommodate a fast-growing urban population. In the best cases, empirical studies in these two regions have been applied in analyses using aggregate data, while the present study uses disaggregate data. This paper includes an original, empirical study based on data collected by a co-author of this paper (Ibrahim 2017b), the results of which have also been published in form of data (Ibrahim 2017a). Both the mentioned publications reflect the full details of the data collection as well as the descriptive statistics. The present study adds statistical analysis and correlation study to the abovementioned dataset. However, in the present paper, important parts of the descriptive statistics especially those related to the variables used in this study have been described once again to help readers understand the details of the data collection and do not need to refer to the previous publications of about the survey and data.

The topic of this study is in relation with urban mobility and house location selection. It is assumed that the residential location choices can generally be or not in 
relation with urban transportation, especially commuting. In other words, selecting the location of a house does not make any difference to the correlations with urban mobility, if the house is going to be rented or purchased. However, beyond this assumption that simplifies the analyses, readers can find some inputs about the correlations of rental prices with other factors in this paper.

Some parts of this paper deal with the notions of developed and developing countries, so these phrases need to be explained before empirical parts of the study. Since the urban travel behaviours and location choices are highly in association with socio-economics of urban dwellers, the definition of developed and developing worlds, on which the contextual analyses of this study stand, is based on economic phenomena. The mostly used definition of this type is presented by the United Nations, in which a developing country is a country with a less developed industrial base (industries) and a low human development index (HDI) relative to other countries. The gross domestic production (GDP) of countries has an important role, so this definition reflects the nature necessities of this study including urban life decisions, lifestyles, and mobility habits, which are closely linked to economies, according to a large part of the urban travel behaviour research.

The first part of the paper introduces the topic to the readers. Informed by the literature review, it also highlights the problem statement and the objectives of this study. The next part describes the opted methodology of this paper. Mainly, it reports on the research questions and hypotheses, survey characteristics, data collection, and analysis methods. The third section of the paper presents the study findings. This section mainly revolves around the correlation of residential location choice decisions with the studied factors and a comparison of residential location choices. The last parts of the paper provide a discussion based on the study findings, which pave the way to finally conclude the study.

\section{Methodology}

\section{Research Questions and Hypotheses}

The present study seeks to answer the following research questions: (i) "How are the main drivers behind residential location choices in Alexandria connected to various socio-demographic groups or people with different accessibility levels to urban and built environments? (In other words, how are these reasons distributed among different groups of people?)", (ii) "How are the main residential self-selections in Alexandria associated with one another and which are the most important?", (iii) "How are the housing location-related decisions of Egyptians similar to or different from international decisions?", and (iv) "How can planners and decision-makers use the knowledge produced by this study for urban planning and housing in Egypt?".

\section{Materials}

Ibrahim (2017a, b) conducted a residential location choice study in Alexandria - one of the cities of Egypt — with a population size of 4,546,231 in 2014 (CAPMAS 2014). The main rationale of choosing Alexandria as the case study area was primarily due to two reasons. Firstly, it is the second largest city of the Egypt, and secondly, it is experiencing 
fast paced urban development as New Borg El-Arab (one of the new cities) is located within the urban boundary of Alexandria (Ibrahim 2017a, b). Quantitative methods were used to carry out the field investigations. A sample size of 224 with a confidence level of $95 \%$ and precision of \pm 6.55 was selected. A multi-stage sampling technique was applied to distribute the sample among the target population. In the first stage, eight districts of Alexandria with varying population sizes were selected, and a sample was distributed among them by applying weights in proportion to the respective population size. The same procedure was repeated in the second stage for the selection the Sheykhat from the already selected districts, and the sample was again distributed among them by their population sizes. Lastly, in stage 3, random sampling was applied to recruit households for the survey. The survey questionnaire was comprised of 16 questions grouped in three sections which were socio-economic having 5 questions, housing unit characteristics with 7 questions, and housing demand characteristics (4 questions). The first section inquired about the variables of age, gender, marital status, employment, and travelling modes owned. Next section investigated the dwelling unit characteristics, including housing type, the reason for choosing the current living place, travel time, the mode used, history of change of housing location, housing tenure and housing units owned, and rental payments where applicable. The last section dealt with the future intentions of the respondents concerning change of housing location, the location preferences, reasons behind the preferred locations, and anticipated housing tenure.

In order to answer the research questions of this study, the focus is put on one of the questions of the survey instrument asking about the main reasons of residents for choosing the location of the house they currently live in question 8- "How did you choose the place you are living in now?". The respondents were asked to choose three out of the eight possible options. The options were "I afford this house", "proximity to work", "family's asset”, "availability of transportation", "nice neighbourhood", "proximity to family/relatives", "nearby downtown", and "social standing of the area". During a pilot survey as well as the personal experience and judgement, the researchers concluded that social and family-related options should be added to the questionnaire; thus, options like living in a house that has been the family's asset or living near to the family, friends, and relatives were added. There were two options related to mobility and transportation: availability of transportation systems such as public transit and paratransit and proximity to work, which indirectly refers to commuting. The social aspects of the house's surrounding area were addressed by the "nice neighbourhood" option; this can reflect a variety of spatial and socio-economic factors. Another option addresses a combination of different aspects of urban life: proximity to downtown. This option is related to transportation and social aspects. Here, we classify it as a social issue, so the main mobility-related options are proximity to work and accessibility to transportation.

For analysing the circumstances and functions of these location choices, a variety of factors, including demographic, social, infrastructural, and mobility-related variables, were removed from the survey results. The factors that were subsequently tested for their correlation with location choices were all categorical: age, gender, marital status, employment, individual (or household) car ownership, tenure type, unit price (if it is owned by the respondent's family) or rental price (if it is rented), type of house (private, public, cooperative, self-built, etc.), time to go to work (if employed), transport mode of commuting, residential mobility (they were asked if they had already changed homes in the past; some people traditionally live in the house inherited from their parents), the 
period of changing homes (if they had moved, how long ago), and reason for relocating. Table 5 in Appendix illustrates the frequencies and classes of the categorical variables, including the dependent variables of this study (residential location choices).

\section{Analysis}

A combination of quantitative methods is used to answer the research questions. Because of the categorical nature of the data, a chi-square test of independence is applied to answer the first and second research questions to find significant correlations and independences. For answering question one, chi-square tests were applied to eight reasons for a location change and 14 variables related to socio-economics, transport characteristics, and space and land use. For answering question two, a chi-square test was applied to the eight reasons for house location decisions. The $P$ value levels of significance were 0.05 for highly significant and 0.1 for marginally significant. The null hypothesis for the chisquare test of independence was that there was no association between the tested variables - in other words, that they are independent. Thus, $P$ values smaller than the significance thresholds indicated that the two variables were associated, while values larger than the significance thresholds showed a significant difference between them. The $P$ values calculated in this study are asymptotic two-sided $P$ values that appeared to have low values compared to the Bonferroni correction method. To answer the last two questions of this research, a literature review was undertaken. The results can be observed in the discussion section. Question three was discussed by addressing international English language publications, many of which came from high-income countries. Research question four was answered by providing a discussion about the findings of this study and the planning practices conducted in Egypt during the recent decades.

\section{Findings}

\section{Correlation of Residential Location Decisions with Different Factors}

The first sub-section of findings deals with the first question of this study. As explained in the Methodology section, eight main reasons for inhabitants' housing location choices were tested for their association with socio-economic and spatial factors via a chi-square test of independence. The results are displayed in Table 1. The null hypothesis of no association between the variables was rejected in several instances, and the respective $P$ values for these cases have been made bold in the table. For example, there is a significant association between proximity to work and the age, gender, marital status, employment, commuting time, transport mode, and residential mobility (those who have relocated) of the respondents. There is also a marginally significant association between proximity to work and unit rents. Availability of transportation has a significant correlation with car ownership and marginally significant correlation with employment and unit price. There are some other interesting outputs; e.g. affordability has a strong significant relationship with commuting time and mode choice. The diagrams in Fig. 2 in Appendix have more information on these associations, where 1 is the selection of the respective reason and 0 is the non-selection of the reason. 


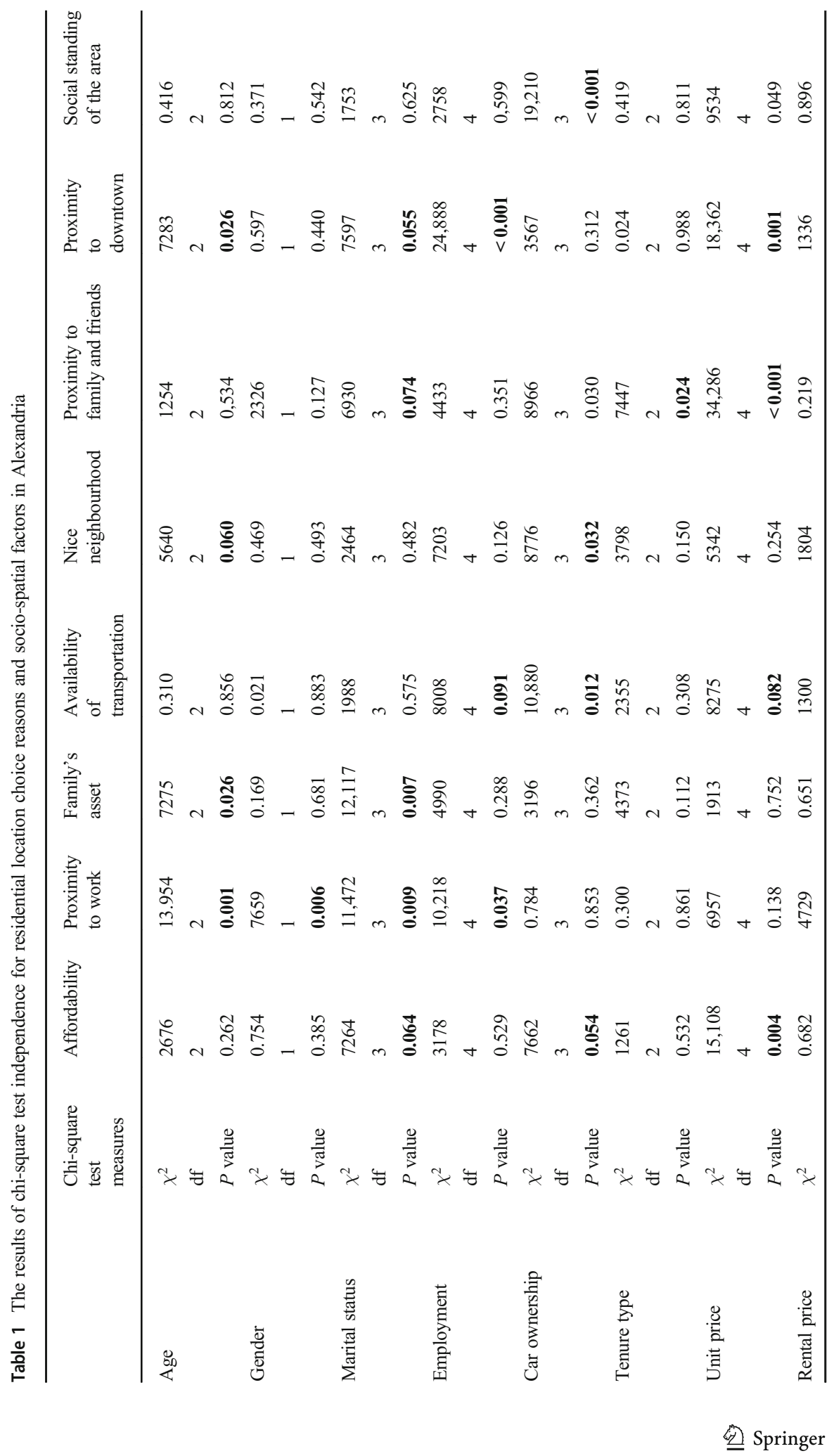




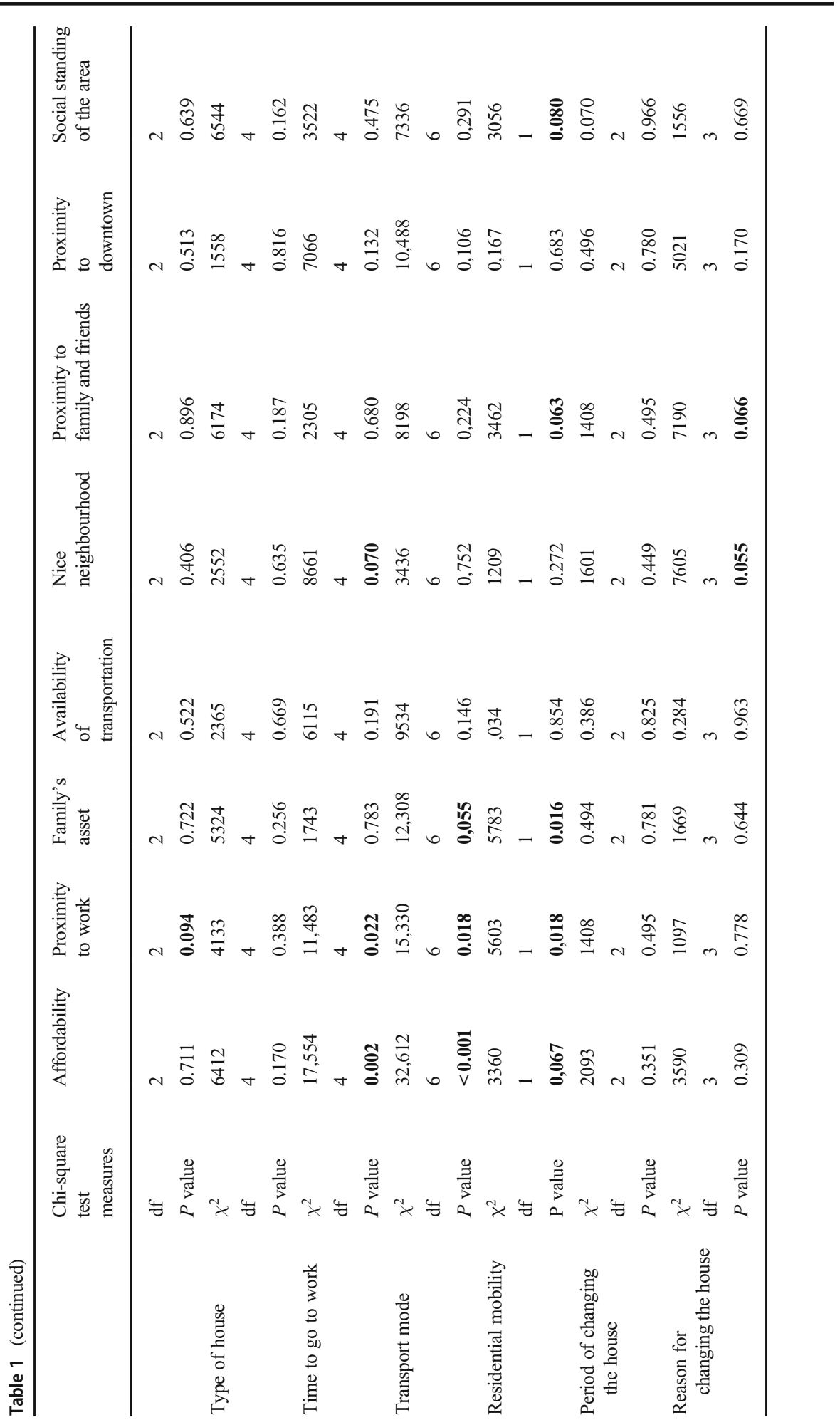




\section{Comparison of Residential Location Choices}

The numerical outputs of this study enable us to compare different location choice causes with one another and understand which are the most influential. The following analysis addresses the second research questions of this study. Figure 1 presents an overview of the findings of the study. Figure 1a displays the eight reasons and their share out of the sample population. Availability of transportation, including public transit and paratransit, is one of the three main reasons for relocation for $42 \%$ of respondents. This factor is followed by a nice neighbourhood and affordability at $37 \%$ and $36 \%$, respectively. This suggests that the main reason is related to transportation, followed by spatial and socio-economic issues. Since the socio-economic reasons were broken down into four different factors (compared to two mobility-related causes), it seems useful to divide the reasons into larger classes: (i) socio-economics, including affordability, proximity to family and friends, family's assets, and social standing of the area; (ii) transport-related issues like availability of transportation and proximity to the workplace; and (iii) spatial factors consisting of neighbourhood quality and proximity to downtown. If so, combined calculation location choices will show a higher percentage for socio-economic reasons (44\%) compared to $30 \%$ for transportation and $26 \%$ for space and the built environment (Fig. 1b).

To address the statistical significance of the differences between the eight reasons and the three categories, a chi-square test of independence was applied to question 8's eight reasons. Table 2 displays the frequencies of answers related to the reasons for location choices in the form of matrices, including $2 * 2$ contingency tables for each pair of variables. This table shows how individuals make complex decisions based on different causes; e.g. for 99 out of 224 respondents, neither affordability nor proximity to work was a reason for choosing their current living place, while 24 other respondents did cite these two reasons. Fifty-five respondents chose affordability, but not proximity to work. The other way around, proximity to work was a reason for 41 of them, while affordability was not among the three reasons.

While this table gives important information, it still does not offer any insight into the significance of the findings. Table 3 explains the statistical significance values from the chi-square independence tests. As explained in the methodology section, $P$ values smaller than 0.05 (or 0.10 ) show that the null hypothesis of no association is rejected, so reasons with $P$ values higher than these thresholds are significantly (or marginally
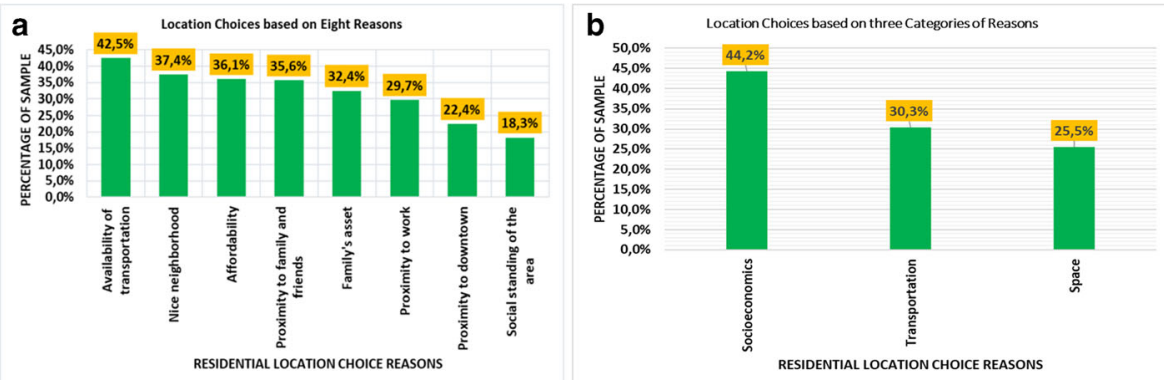

Fig. 1 (a) The eight most important reasons for choosing residential locations and (b) the combined categories based on three most important groups of reasons 


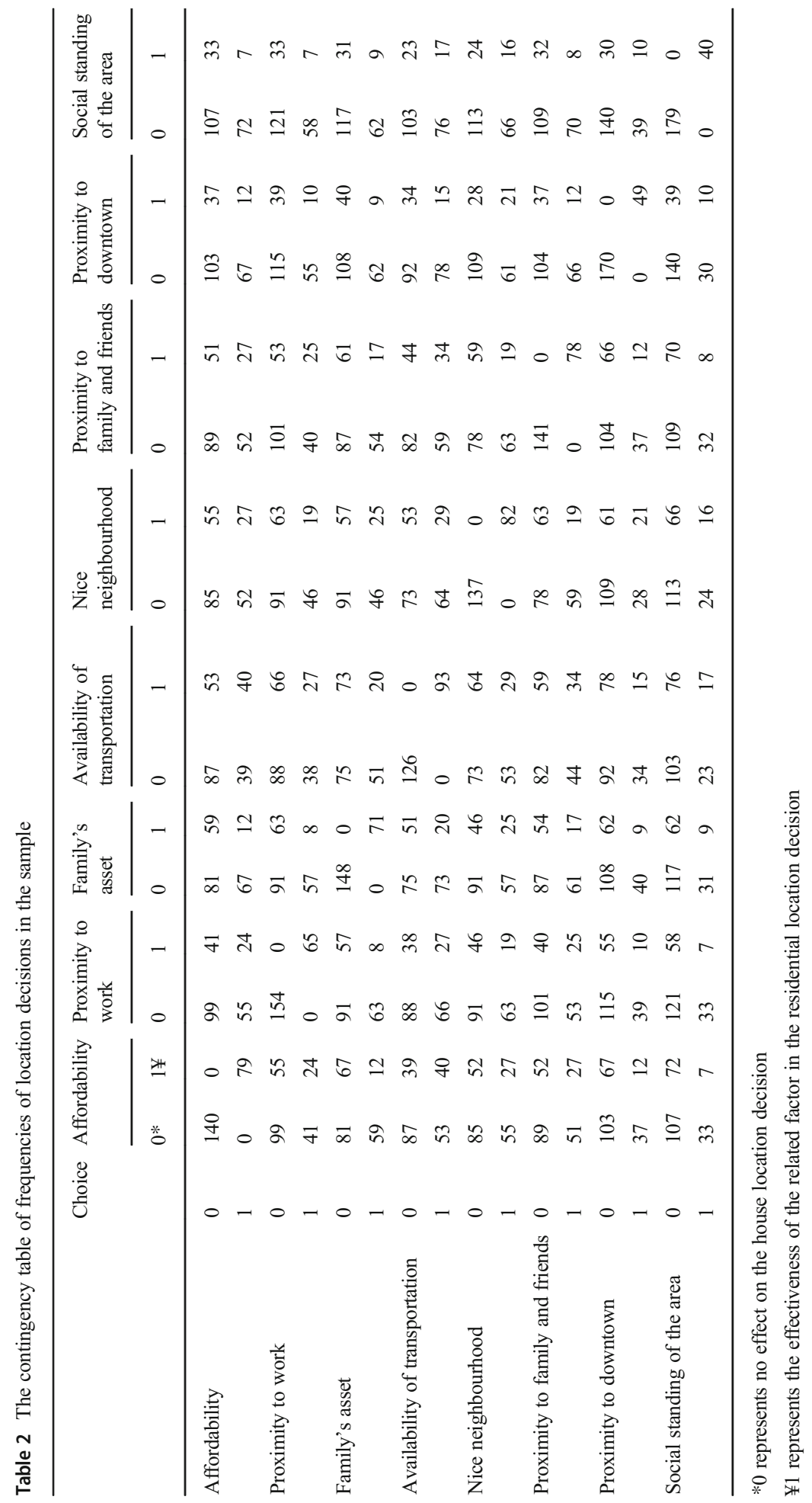


significantly) independent. In other words, with large $P$ values, one of the factors is more effective. By observing the amounts in Table 3, it is possible to say which of the reasons is the effective one; e.g. there is a small $\chi^{2}$ value for the test done for affordability and proximity to work that resulted in a large $P$ value. According to Table 2, affordability is a more important reason compared to proximity to work. These two tables provide evidence for understanding the two-by-two comparison of reasons.

Nevertheless, the question about the groups of motives remains relevant, so another series of chi-square tests were conducted among the three categories, namely, socioeconomics, transportation, and spatial traits. According to Table 4, there is a significant association between only socio-economic reasons and spatial issues $(P=0,029)$. In other words, transport-related causes of housing location choices are not correlated with other reasons. It is worth adding that Fig. $1 \mathrm{~B}$ shows that transportation falls in between socio-economic and spatial reasons in terms of frequency of influencing decisions, but these frequencies were only estimated when a reason was found to be effective (shown as 1 in the contingency tables). In chi-square independence tests, two-by-two contingency tables are the basis of statistical estimations, so the four-cell structure of decisions is more important, e.g. [affordability $=0$, proximity to work $=0$ ], [affordability $=0$, proximity to work $=1]$, [affordability $=1$, proximity to work $=0$ ], and [affordability $=1$, proximity to work $=1$ ] (in all of these tables, 1 presents the effectiveness of a factor in people's decision, while 0 shows no effect).

\section{Discussion}

If all the investigated reasons of residential location choices independent of each other are viewed, "availability of transportation" comes out as the most stated reason by the sampled residents $(42.5 \%)$ of Alexandria for affecting their residential location decisions. This top stated reason was followed by other reasons of "nice neighbourhood" $(37.4 \%)$ and "affordability" (36.1\%). This finding is in conformation with Brenner and Schmid's (2015) debate on dealing the urban challenges. When viewed them collectively, socio-economic factors were the most stated reasons (44.2\%) followed by transportation $(30.3 \%)$ and spatial factors $(25.5 \%)$ affecting the decisions of residential location choices in Alexandria. However, these facts present only the descriptive findings, which have been dealt with in detail by Ibrahim $(2017 \mathrm{a}, \mathrm{b})$. The main purpose of this paper was to investigate deeper into these residential location choices decisions through inferential analyses. Out of so many investigated variables, "car ownership" had the most significant association with the "availability of transportation" with respect to the decisions of residential location choices. This reflects that within the Egyptian context, people who own cars do not bother much for the consideration of the availability of public transportation services while deciding the location of their residential units; alternatively, it is the significant consideration for residential location choices for the people who do not own car. This finding is partly in confirmation with the results of a few studies emerging from the high-income countries. Many of the studies though report on a significant association between the availability of public transportation services and residential location choices (such as Heinen et al. 2018; Scheiner 2014; Boone-Heinonen et al. 2010; Cao et al. 2009; Cao 2014; Næss 2009); only a few of them found a marginal association between attitudes towards travel 


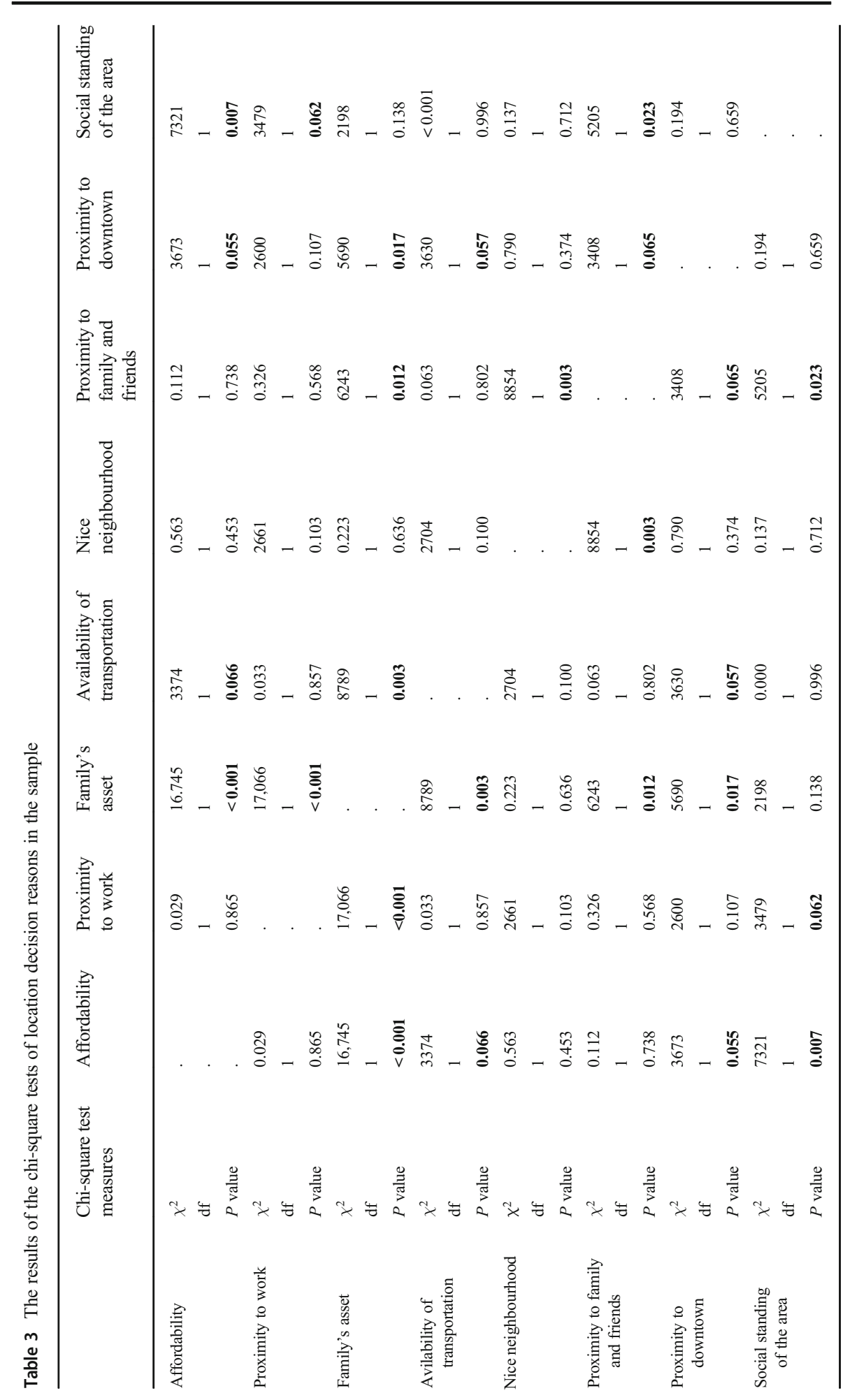


Table 4 The results of the chi-square tests for associations between mobility, socio-economics, and spatial issues as relocation reasons

\begin{tabular}{lllll}
\hline Combined classes of reasons & Chi-square test measures & Transportation & Socio-economic & Space \\
\hline Transportation & $\chi^{2}$ & - & 0.072 & 1380 \\
& df & - & 1 & 1 \\
& $P$ value & - & 0.789 & 0.240 \\
Socio-economics & $\chi^{2}$ & 0.072 & - & 4775 \\
& df & 1 & - & 1 \\
Space & $P$ value & 0.789 & - & $\mathbf{0 . 0 2 9}$ \\
& $\chi^{2}$ & 1380 & 4775 & - \\
& df & 1 & 1 & - \\
& $P$ value & 0.240 & $\mathbf{0 . 0 2 9}$ & - \\
\hline
\end{tabular}

modes and choices made for a residential location (Ettema and Nieuwenhuis 2017; de Vos et al. 2012; Schwanen and Mokhtarian 2004), thus pointing out the insignificant effect of car ownership on the established relationship between the availability of public transportation and residential location choices.

Different types of neighbourhood in Egypt can play a role in the self-selection process within the formal or the informal markets. In different words, there are still a variation of neighbourhoods that are perceived differently in each market, which could lead to different choices within a given market. As an example, based on the preferences and perceptions of the residents and respective limited budget, the most influential priorities are walkability, neighbourhood job opportunities, and the availability of public transport infrastructures related to different modes (Ibrahim and Masoumi 2018). In Egypt, the distance between the neighbourhood and the capital city may influence individual choices, giving that their jobs or family members may live in the capital city (Greater Cairo). Hence, the distance to the capital city could play a role in selecting between neighbourhoods in different new cities based on how far they are from the capital (Ibrahim and Masoumi 2016). A deeper inquiry into the reason of "nice neighbourhood" for selecting housing location also revealed that the most significant variable that affects this factor is the "car ownership". It again shows the travel attitude and the importance of car ownership within the Egyptian context. Car ownership (64.7\% in the studied sample of Alexandria) has become a central element in the decision-making process of Egyptian society due to not having a decent and efficient public transport system in the Egyptian cities (Ibrahim 2017a, b; El Araby 2013). Owning the car makes the residents independent of transportation factors while deciding the location of their residential units and spatial factors such as "nice neighbourhood" dominates the decision-making process. Concerning "affordability", transport mode has been revealed as the most significant factor for the people who stated "affordability" as a reason for their residential location choice. This gives a clue that affordability is a condition that is shaped up with many factors, including the availability of transportation modes for meeting the mobility needs. People perceive affordability not only as of the price or rent of the residential unit, but they also consider the living costs of a particular location with respect to their mobility-related expenditures 
as well (Pagliara et al. 2002). This finding is in accordance with the debate put up by Kreckler (2015) and Sims (2012) where they suggested that the discussion of housing affordability should consider the housing location as well for a better understanding. This result also finds similarity with the outcomes of a few studies conducted within the context of the developing world. Azmoodeh et al. (2020) and Alas (2020) also found a correlation between the housing price (which mainly determines the affordability as defined by LEEDS 2015) and accessibility to the transportation services in Tehran and Istanbul, respectively. If we look at the number of significant associations that a variable establishes with the stated reasons of residential location choices, "marital status" and "residential mobility" come out as the most significant variables (five significant associations each). A deeper look reveals that these are mainly the married people (51.8\%) and those who have changed their housing units (52.3\%), majorly within a past period of 2 to 10 years (56.9\%), whose residential location choices matter the most.

When these reasons have been investigated together for having any association between them, interesting results have also been revealed. The reason for "availability of transportation" has the most significant association with another reason for "family's asset". Generally, the residential units which are used by more than one generation as a family's asset belong to older areas of the city which have a better connection to transportation infrastructure as compared to the newly developed parts of the city (El Araby 2013). The second most stated reason of "nice neighbourhood" for residential location choices has been found significant with only one other reason of "proximity to family and friends". It gives an insight that the reason of a nice neighbourhood is not only a spatial characteristic, but there also lies some element of social character as well. Other than the built-up environment, it is also the proximity of family and friends, which makes a living neighbourhood "nice", and it may also affect the residential self-selection process (Sims et al. 2008). This interpretation is also strengthened by the finding that when all the reasons are grouped in three broad classes and investigated together for having an association among them, it was found only in between socio-economic and spatial factors. Understandably, "affordability" has been found highly significant with the reason of "family's asset". As such family's houses are inherited to the next generations, they are generally found as affordable to their occupants. If the frequency of the relationships among these reasons is seen, the reason of "family's asset" found the factor having the highest number of highly significant associations with as many as five other factors (out of total seven). Only the reasons of "nice neighbourhood" and "social standing of the area" have been found to have an insignificant association with the reason of "family's asset". It depicts that, though it stands out at rank 5 concerning the frequency of the stated reasons individually, it is the most significant reason having its effect on other stated reasons. It also provides an understanding that such residential units are located in the older parts (proximity to downtown) which have mixed land uses (proximity to work), accessibility to transportation infrastructure (availability of transportation), and social networking (proximity to family and friends).

The topics of housing affordability and market conditions within the context of Egyptian cities have been studied by many scholars (such as Sims 2012, 2015; Fahmi and Sutton 2008) to report on the housing situation and pertinent challenges; however, this study provides empirically tested evidence-based significant findings related to the process of residential location choices in Egyptian cities to inform the housing policy for key interventions. Egypt launched the National 
Housing Program in 2005 (Hussein et al. 2014) in a bid to meet the excessive housing demand by developing new cities within the urban boundaries of older cities. However, the main focus remained on the supply of the housing units instead of mending the flaws in the housing policies (Ibrahim 2017a, b). The key findings of this study suggest integrating the transportation planning with the housing development sector as it is found that many of the residential location choices are based on transportation factors, mainly the availability of public transport, car ownership, and transport modes. It is in confirmation with the findings of recent relevant studies conducted both in developed (Bruns and Matthes 2019; Ho et al. 2017) and developing countries (Acheampong 2018). This provides a rationale that the Egyptian government needs to invest in the public transport sector to make it integrated and efficient simultaneously to the development of new cities to address the housing needs. This policy intervention will also address the high car ownership rates in Egyptian dense cities (El Araby 2013) which is in contradiction to the JICA's (2011) finding that cities with higher densities tend to have low car ownership rates. Another important finding of the study revealed the importance of the "family's asset" of the housing units. Generally they are the older housing units located within or close to downtown areas, thus offering certain benefits to its occupants with respect to its location and affordability. In the recent decades, the Egyptian government has developed many new cities for the housing supply; however, the initiative failed to attract a significant population to reside there (UNICEF 2010) despite offering job opportunities (NUCA 2016). Many of these new cities have more than $40 \%$ vacancy rates (World Bank 2008). This shows a shift in the government housing policy from peripheral new developments to the strengthening of inner-city areas needed. However, the intended policy shift also requires addressing the issue of significant vacancies of residential units in inner-city areas (Rust and Gavera 2013) due to unaffordability, poor conditions (Ibrahim 2017a, b), outdated rent control system, and the norm of keeping the additional housing units vacant for the children after marriage or for investment (Sims et al. 2008; World Bank 2008). Informed by the findings of this study, these are the priority areas which Egyptian government need to consider while devising any housing policy in the future.

\section{Conclusion}

To simple frequency, the "availability of transportation" followed by "nice neighbourhood" and "affordability" emerges as the top stated reason for residential location choices in Alexandria. When these stated reasons were analysed for having any association with the socio-economic, transportation, and spatial variables, "car ownership" and "transport mode" have been found to have the underlying effect on the stated preferences which shows the importance of integrating transport planning with the housing area development. With respect to the frequency of these associations, "marital status" and "residential mobility" have been found the most significant variables to understand the residential location choices better. When the reasons of residential location choices were analysed together for testing any association between them, the top stated reasons found to have a significant association with other reasons 
of "family's asset" and "proximity to family and friends". When we look at the reason having the most number of significant associations with other stated reasons, again "family's asset" comes out as the leading reason. These findings are partly in confirmation with many of the studies conducted within the context of high-income countries. However, the main deviation found is the role of "family's asset" reason which has found to have the most significant effect on other stated reasons. This shows the difference between the cultural setting and its impact on the study findings. The main policy recommendations informed by the study findings are the integration of transportation planning with housing development, a shift from peripheral development to regenerating inner-city areas and housing sector policy reforms.

Egyptian cities are undergoing a regime of developing new cities to tackle the housing shortage. However, the evidence suggests that such efforts are not bringing the required results as the vacancy rates in such new developments are still significantly high. This highlights the importance of learning from the shortcoming of the National Housing Program to steer the future course of action in the right direction. Firstly, it is understood from the study findings that the integration of public transport planning with the housing area development is of paramount importance for meeting the mobility and accessibility needs of the people. Secondly, compact development has to be promoted to strengthen the inner cores of the cities instead of peripheral sprawl development. Thirdly, policy reforms are needed to rejuvenate the housing sector, such as updating the outdated rent control system to stimulate the housing supply and bringing some taxation regime to discourage the speculation of housing units for future interests.

Mainly, the chi-square testing was applied to find associations among the study variables. The test results were then explained for a better understating of the residential location choices within the Egyptian context. However, it is important to highlight a few limitations of the study. The sample size of the study is small as compared to the similar type of studies conducted elsewhere. This limitation cautions against the generalization of the results for other Egyptian cities. Secondly, in the absence of any dependency test, it is difficult to identify dependent and independent variables out of any established association. Due to that reason, cause and effect relationships among the study variables cannot be drawn, which otherwise could prove another important contribution for relevant policy formulation. Finally, it is suggested to investigate the topic further through some correlational studies investigating relationships between the current residential choices of the people and their future preferences for housing locations. This will also assist the relevant government sectors to frame their policies informed by the people preferences and choices.

Funding Open Access funding enabled and organized by Projekt DEAL.

Data Availability Ibrahim, MR; (2017) A dataset of housing market and self-attitudes towards housing location choices in Alexandria, Egypt. Data in Brief, 11 pp. 543-545. https://doi.org/10.1016/j.dib.2017.02. 052. https://discovery.ucl.ac.uk/id/eprint/10072376/

\section{Compliance with Ethical Standards}

Conflict of Interest The author declares that they have no conflict of interest.

Code Availability Not applicable. 


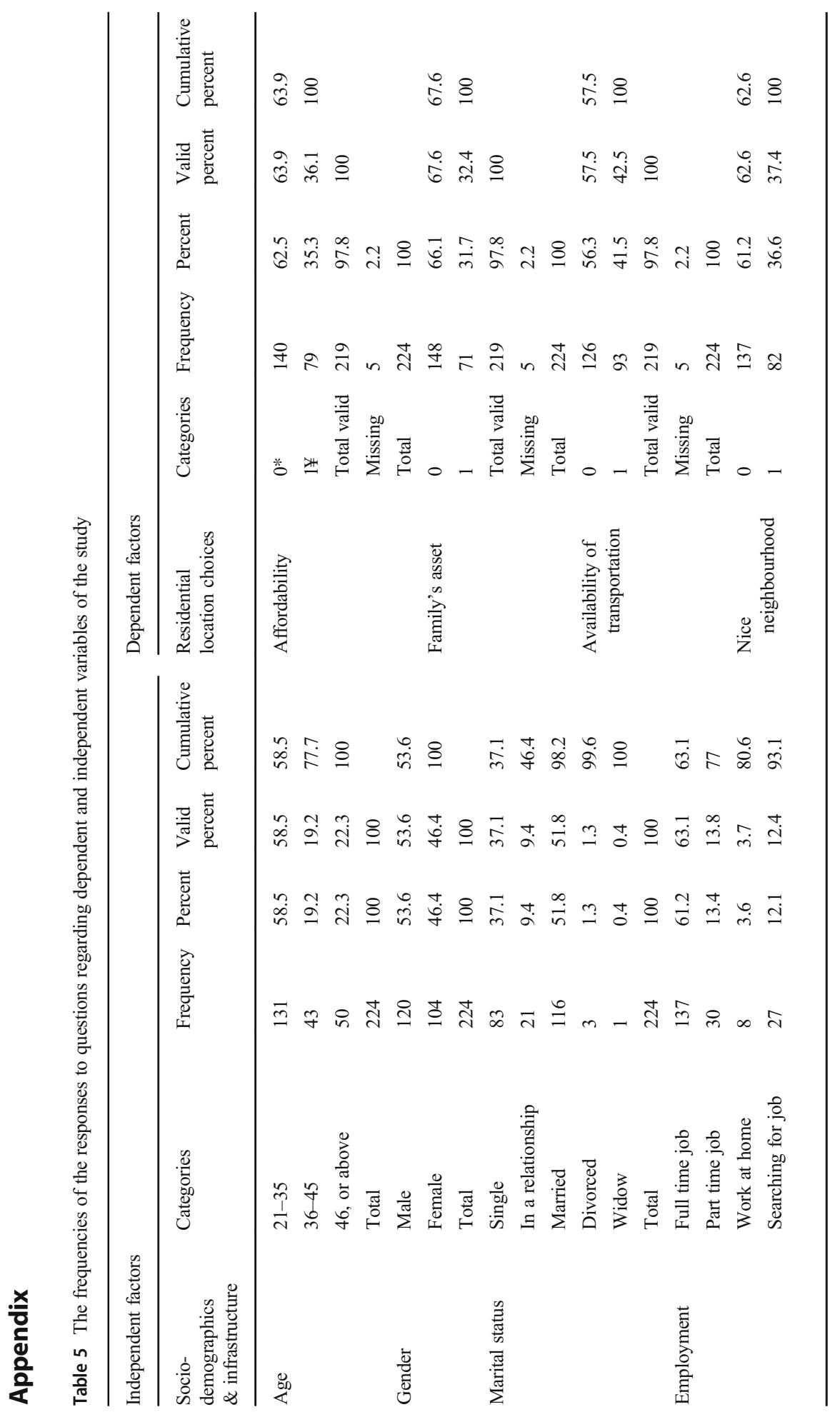




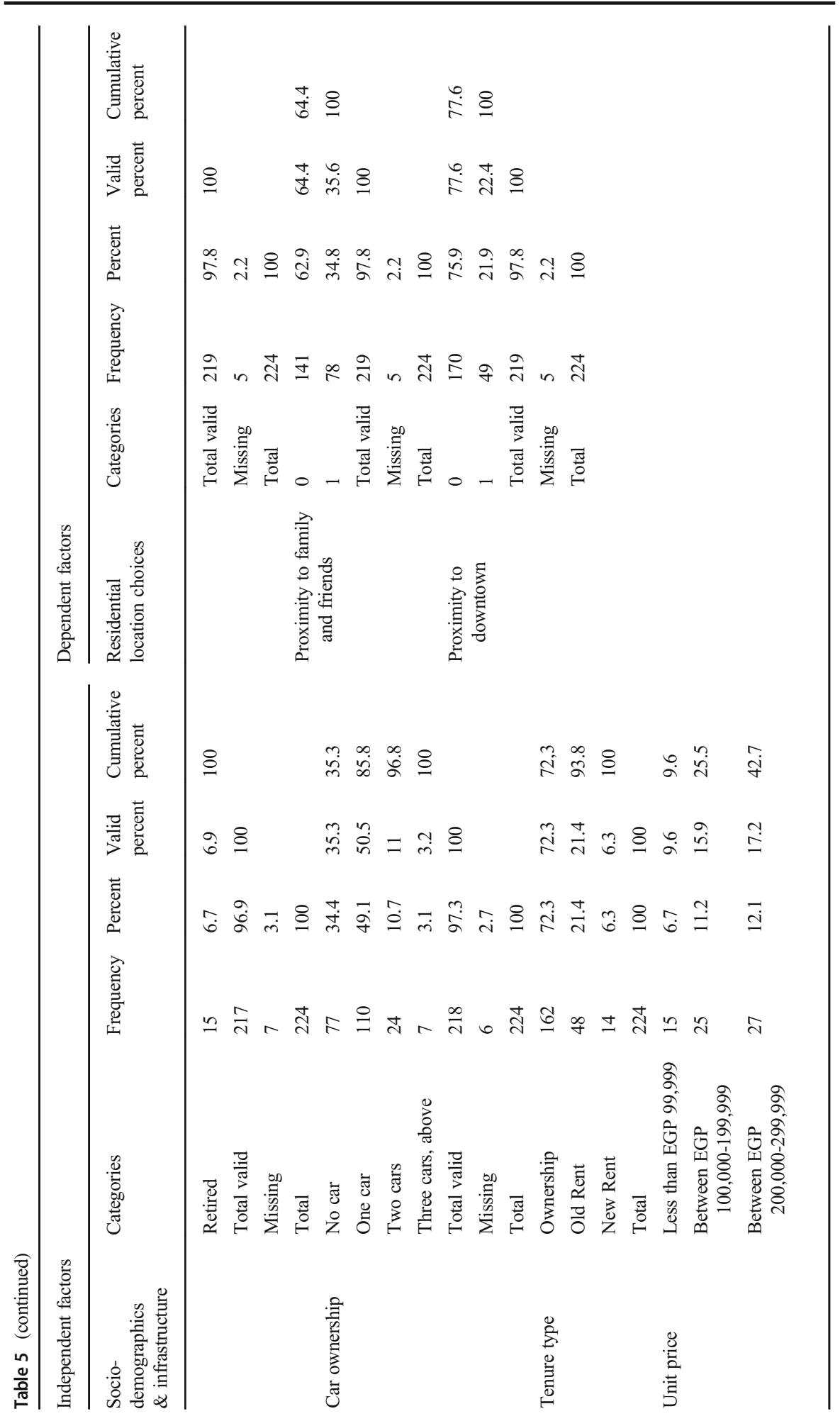




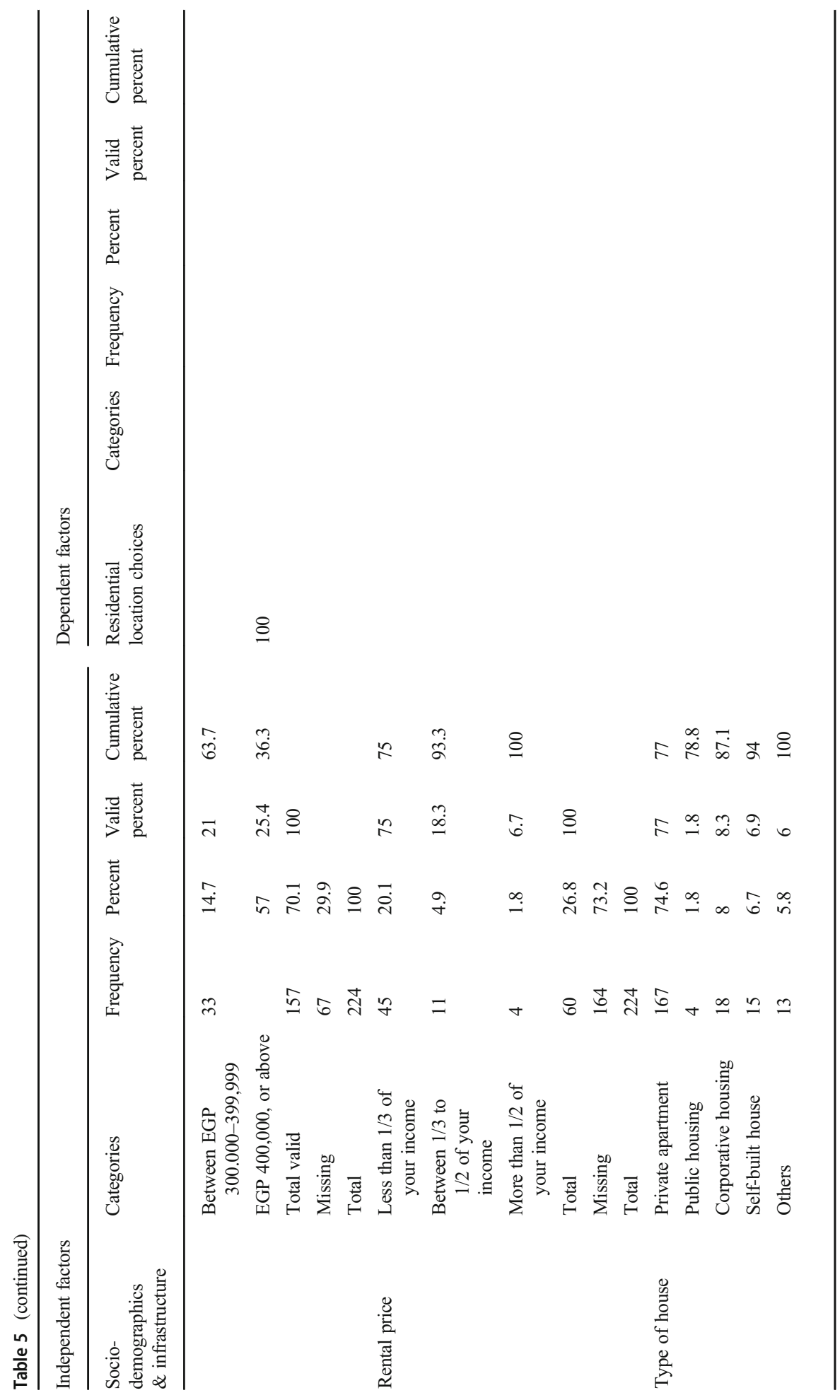




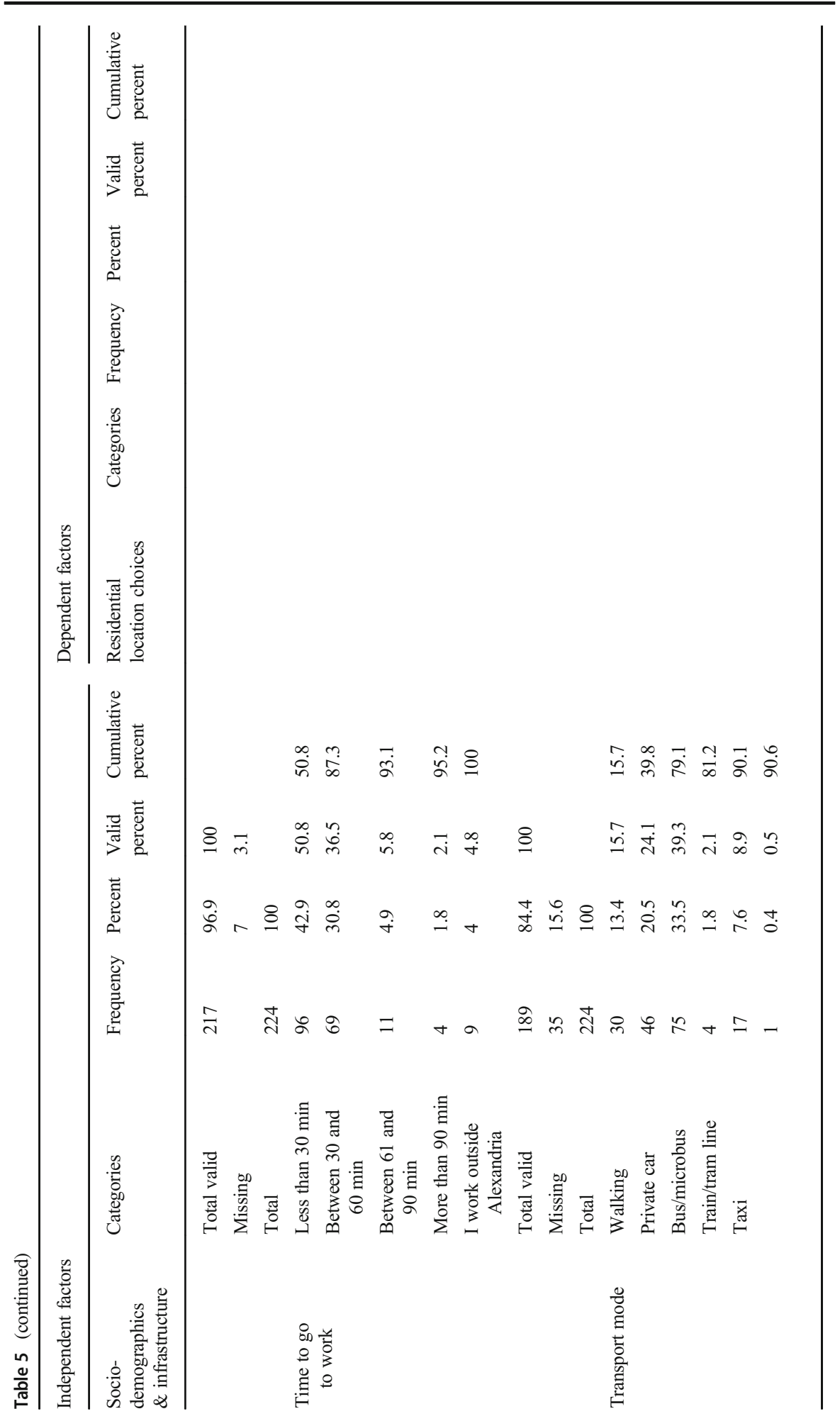




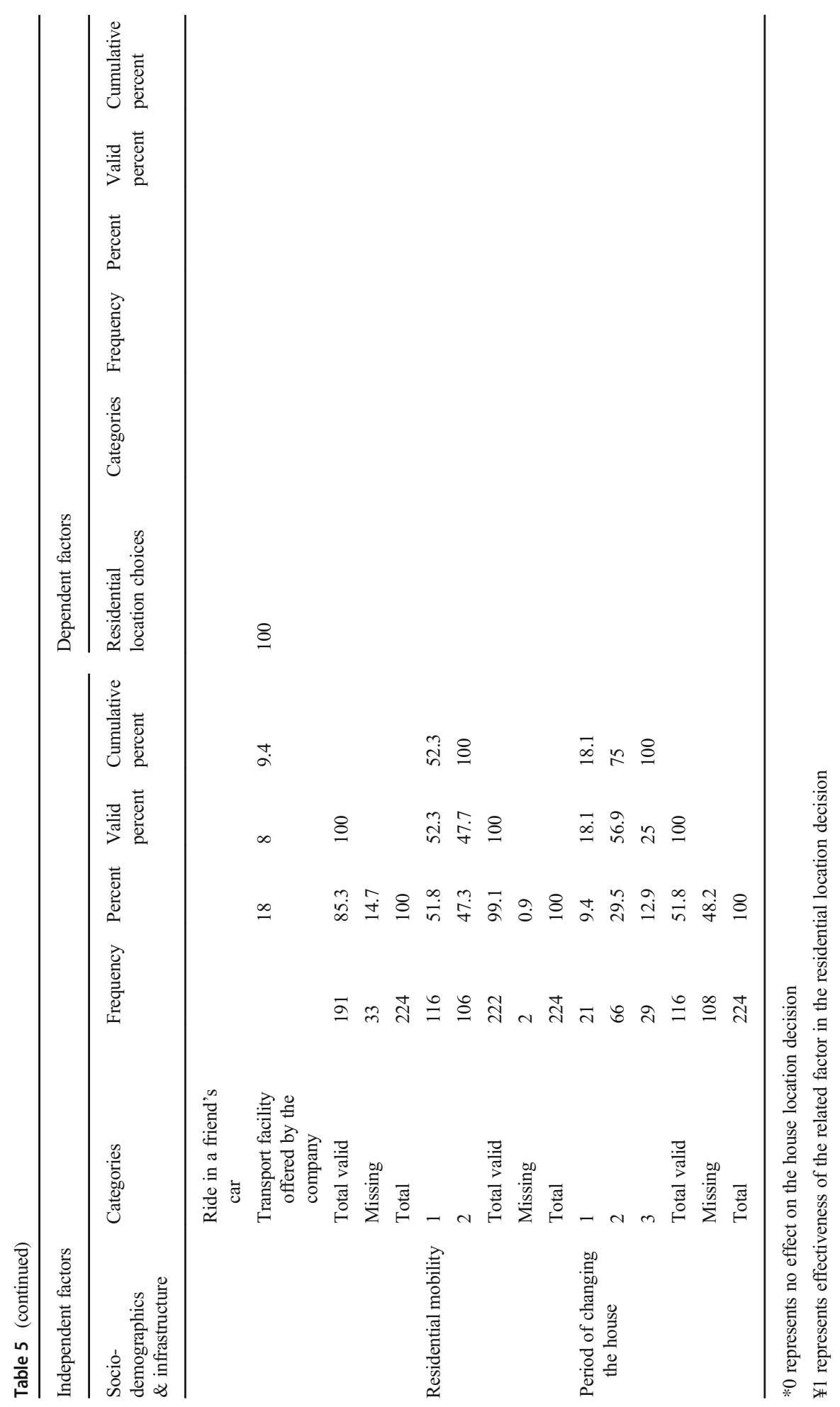




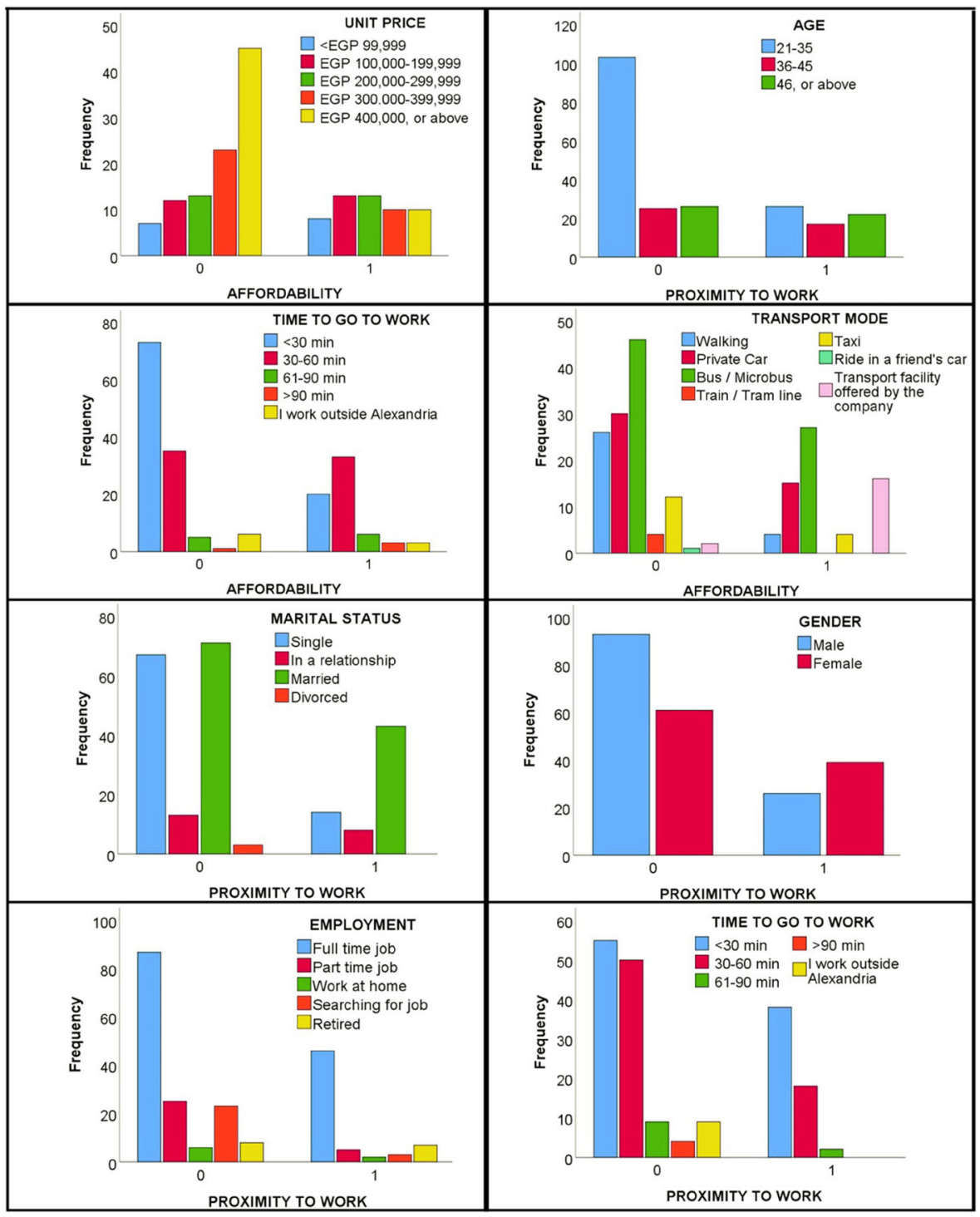

Fig. 2 The significantly correlated variables with location choice reasons $(p<0.05)$ 


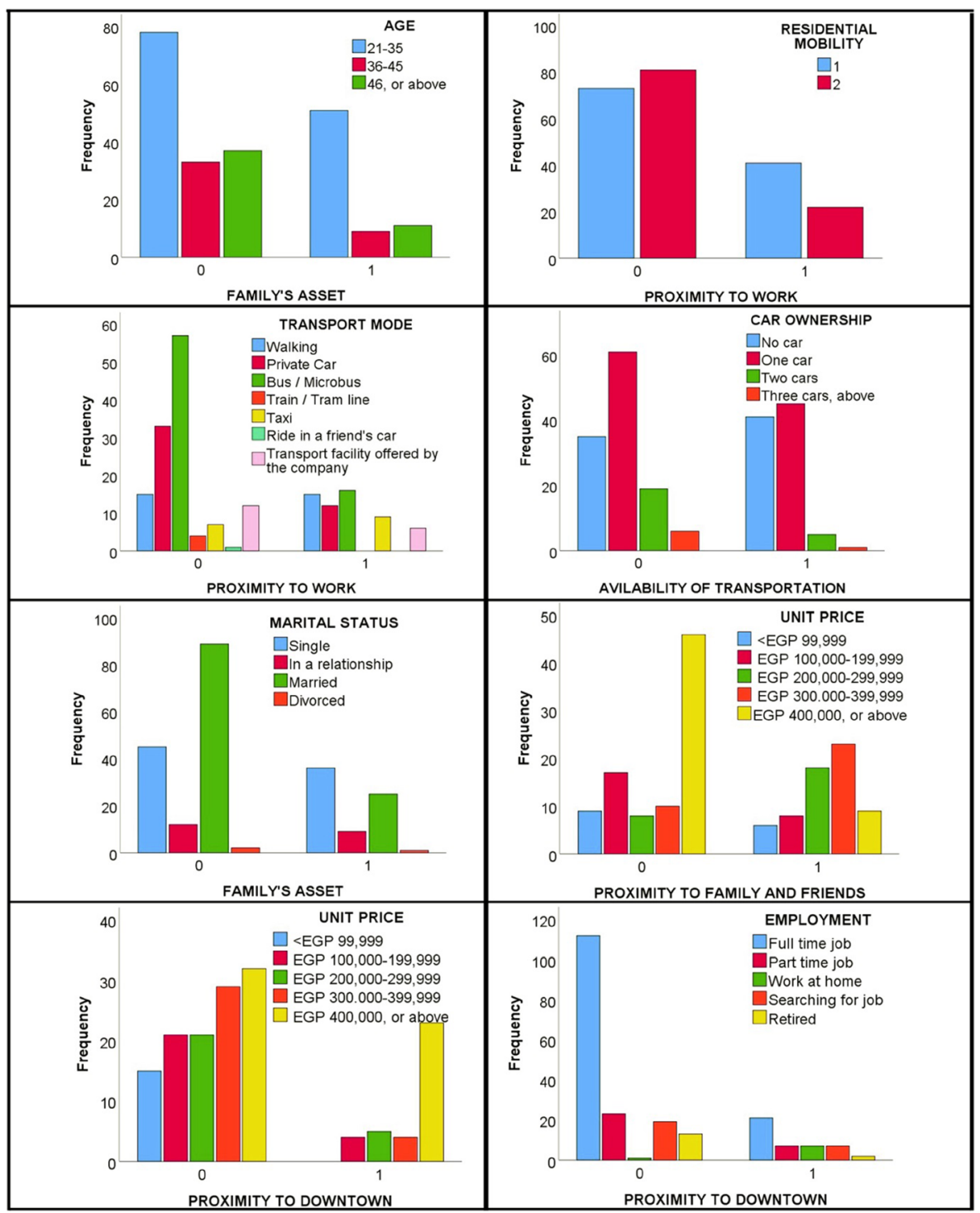

Fig. 2 (continued) 


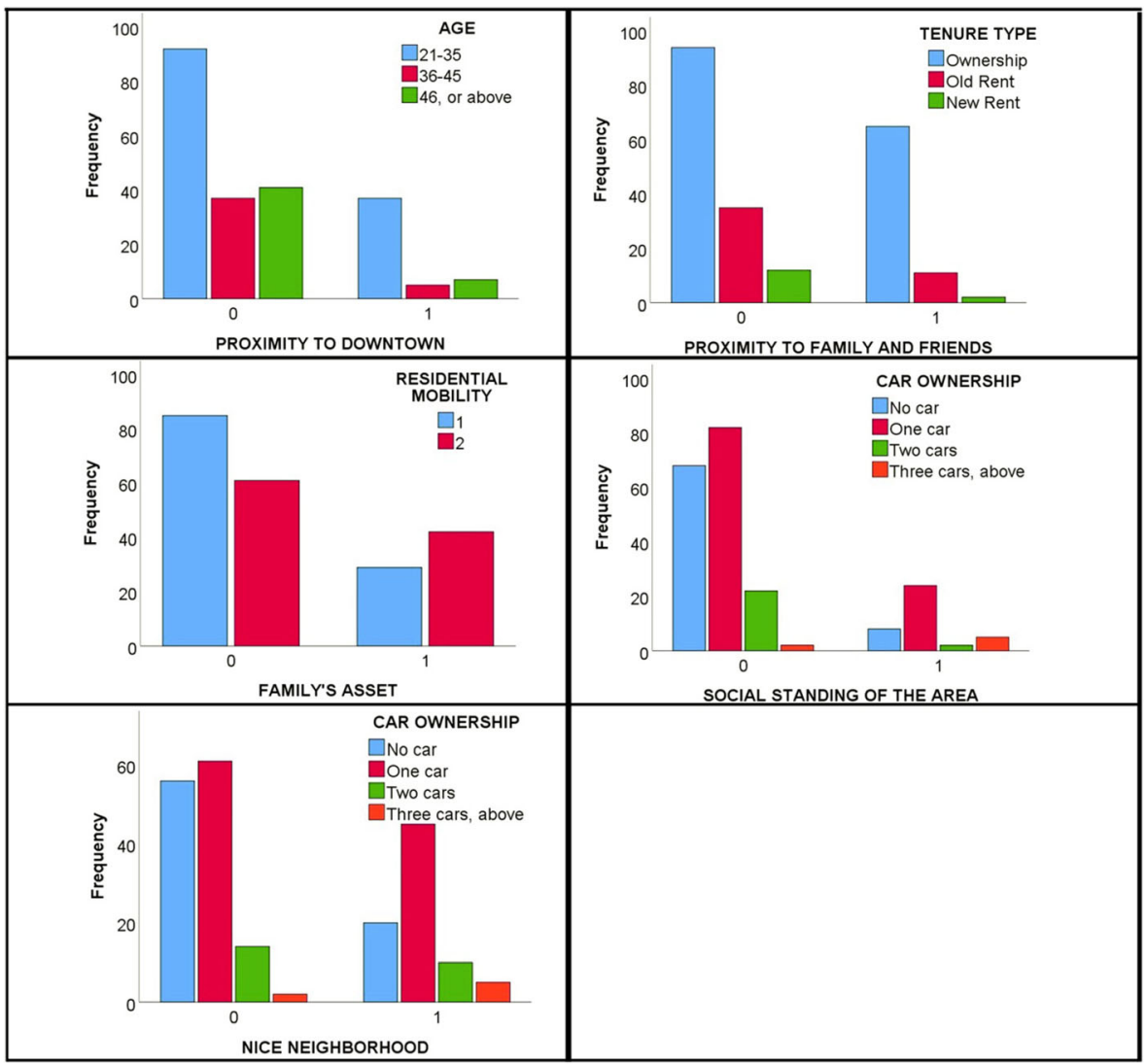

Fig. 2 (continued)

Open Access This article is licensed under a Creative Commons Attribution 4.0 International License, which permits use, sharing, adaptation, distribution and reproduction in any medium or format, as long as you give appropriate credit to the original author(s) and the source, provide a link to the Creative Commons licence, and indicate if changes were made. The images or other third party material in this article are included in the article's Creative Commons licence, unless indicated otherwise in a credit line to the material. If material is not included in the article's Creative Commons licence and your intended use is not permitted by statutory regulation or exceeds the permitted use, you will need to obtain permission directly from the copyright holder. To view a copy of this licence, visit http://creativecommons.org/licenses/by/4.0/.

\section{References}

Acheampong, R. A. (2018). Towards incorporating location choice into integrated land use and transport planning and policy: A multi-scale analysis of residential and job location choice behaviour. Land Use Policy, 78, 397-409.

Ahmad, N. (1993). Choice of neighbourhoods by mover households in Karachi. Urban Studies, 30(7), 12571270. 
Alas, B. (2020). A multilevel analysis of housing submarkets defined by the municipal boundaries and by the street connections in the metropolitan area: Istanbul. Journal of Housing and the Built Environment, 1-17.

Aslam, A. B., Masoumi, H. E., Naeem, N., \& Ahmad, M. (2019). Residential location choices and the role of mobility, socioeconomics, and land use in Hafizabad, Pakistan. Urbani izziv, 30(1), 115-128.

Azmoodeh, M., Haghighi, F., Motieyan, H., Maghsoodi, T., \& Mohammad, J. (2020). Investigating the relationship between housing policy and accessibility, based on developing a multi-perspectives accessibility index: A case study in Tehran, Iran. Journal of Housing and the Built Environment, 1-23.

Baraklianos, I., Bouzouina, L., Bonnel, P., \& Aissaoui, H. (2018). Does the accessibility measure influence the results of residential location choice modelling? Transportation, 8, 11.

Bayoh, I., Irwin, E. G., \& Haab, T. (2006). Determinants of residential location choice: How important are local public goods in attracting homeowners to Central City locations? Journal of Regional Science, 46(1), 97-120.

Boone-Heinonen, J., Guilkey, D. K., Evenson, K. R., \& Gordon-Larsen, P. (2010). Residential self-selection bias in the estimation of built environment effects on physical activity between adolescence and young adulthood. International Journal of Behavioral Nutrition and Physical Activity, 7(1), 70.

Brenner, N., \& Schmid, C. (2015). Towards a new epistemology of the urban? City, 19(2-3), 151-182.

Bruns, A., \& Matthes, G. (2019). Moving into and within cities-interactions of residential change and the travel behavior and implications for integrated land use and transport planning strategies. Travel Behaviour and Society, 17, 46-61.

Cao, X. (2014). Residential self-selection in the relationships between the built environment and travel behavior. Introduction to the special issue. Journal of Transport and Land Use, 7(3), 1-3.

Cao, X., \& Yang, W. (2017). Examining the effects of the built environment and residential self-selection on commuting trips and the related CO 2 emissions: An empirical study in Guangzhou, China. Transportation Research Part D: Transport and Environment, 52, 480-494.

Cao, X., Handy, S. L., \& Mokhtarian, P. L. (2006). The influences of the built environment and residential self-selection on pedestrian behavior: Evidence from Austin, TX. Transportation, 33(1), 1-20.

Cao, X., Mokhtarian, P. L., \& Handy, S. L. (2009). Examining the impacts of residential self-selection on travel behaviour: A focus on empirical findings. Transport Reviews, 29(3), 359-395.

CAPMAS. (2014). The statistical year book. Central Agency for Public Mobilization and Statistics.

de Palma, A., Motamedi, K., Picard, N., \& Waddell, P. (2005). A model of residential location choice with endogenous housing prices and traffic for the Paris region.

De Vos, J., \& Witlox, F. (2016). Do people live in urban neighbourhoods because they do not like to travel? Analysing an alternative residential self-selection hypothesis. Travel Behaviour and Society, 4, 29-39.

de Vos, J., Derudder, B., van Acker, V., \& Witlox, F. (2012). Reducing car use: Changing attitudes or relocating? The influence of residential dissonance on travel behavior. Journal of Transport Geography, $22,1-9$

De, U. K., \& Vupru, V. (2017). Location and neighbourhood conditions for housing choice and its rental value. Int J of Hous Markts and Analy, 10(4), 519-538.

Digambar, A. P., Das, A., Mazumder, T. (2010). Residential location choice: A study of household preferences for the city of Nagpur. Available online at https://scholar.google.com/citations?user= gqh2kagaaaj\&hl=en\&oi=sra.

El Araby, K. (Ed.) (2013). Urban transport issues in Egypt. International Symposium Mobility and Infrastructure, El Gouna.

Ettema, D., \& Nieuwenhuis, R. (2017). Residential self-selection and travel behaviour: What are the effects of attitudes, reasons for location choice and the built environment? Journal of Transport Geography, 59, $146-155$.

Fahmi, W., \& Sutton, K. (2008). Greater Cairo's housing crisis: Contested spaces from inner city areas to new communities. Cities, 25(5), 277-297.

Fatmi, M. R., Chowdhury, S., \& Habib, M. A. (2017). Life history-oriented residential location choice model: A stress-based two-tier panel modeling approach. Transportation Research Part A: Policy and Practice, 104, 293-307.

Frank, L. D., Saelens, B. E., Powell, K. E., \& Chapman, J. E. (2007). Stepping towards causation: Do built environments or neighborhood and travel preferences explain physical activity, driving, and obesity? Social Science \& Medicine, 65(9), 1898-1914.

Guidon, S., Wicki, M., Bernauer, T., \& Axhausen, K. (2019). The social aspect of residential location choice: On the trade-off between proximity to social contacts and commuting. Journal of Transport Geography, $74,333-340$.

Handy, S. L., \& Clifton, K. J. (2001). Local shopping as a strategy for reducing automobile travel. Transportation, 28(4), 317-346. 
Heinen, E., Mackett, R., van Wee, B., Ogilvie, D., \& Panter, J. (2018). Residential self-selection in quasiexperimental and natural experimental studies. An extended conceptualization of the relationship between the built environment and travel behavior. Journal of Transport and Land Use, 11(1), 939-959.

Heldt, B., Gade, K., \& Heinrichs, D. (2016). Determination of attributes reflecting household preferences in location choice models. Transportation Research Procedia, 19, 119-134.

Ho, C. Q., Hensher, D. A., \& Ellison, R. (2017). Endogenous treatment of residential location choices in transport and land use models: Introducing the MetroScan framework. Journal of Transport Geography, 64, 120-131.

Hu, L., \& Wang, L. (2019). Housing location choices of the poor: Does access to jobs matter? Housing Studies, 34(10), 1721-1745.

Humphreys, J., \& Ahern, A. (2019). Is travel based residential self-selection a significant influence in modal choice and household location decisions? Transport Policy, 75, 150-160.

Hussein, H., Darwish, N., \& Salem, E. (2014). Ibni Betak: not just a backyard. مؤن ات كية اهند

Ibrahim, M. R. (2017a). A dataset of housing market and self-attitudes towards housing location choices in Alexandria, Egypt. Data in Brief, 11, 543-545.

Ibrahim, M. R. (2017b). How do people select their residential locations in Egypt? The case of Alexandria. Cities, 62, 96-106.

Ibrahim, M. R., \& Masoumi, H. E. (2016). Will distance to the capital city matter when supplying new cities in Egypt? GeoScape, 10(2), 35-52.

Ibrahim, M. R., \& Masoumi, H. E. (2018). The nuances of the supplied urban fabric in the MENA region: Evidence from Alexandria, Egypt. Land Use Policy, 73, 385-399.

Jiao, P., Harata, N. (2007). Residential location choice behavior for different households:Methodology and case study. Proceedings of the Eastern Asia Society for Transportation Studies Vol.6 (The 7th International Conference of Eastern Asia Society for Transportation Studies, 2007): Eastern Asia Society for Transportation Studies, 171. Available online at https://www.jstage.jst.go.jp/article/eastpro/ 2007/0/2007_0_171/_pdf, checked on 4/4/2008.

JICA. (2011). The research on practical approach for urban transport planning. Japan International Cooperation Agency.

Kreckler, L. (2015). What makes housing affordable. Affordable Housing Institute.

Lee, B. H. Y., \& Waddell, P. (2010). Residential mobility and location choice: A nested logit model with sampling of alternatives. Transportation, 37(4), 587-601.

LEED (2015). Innovation: Housing types and affordability. Available online at http://www.usgbc.org/node/ 7433426?return=/credits

Masoumi, H. E. (2013). Residential self-selection and its effects on urban commute travels in Iranian cities compared to US, UK, and Germany. International Journal of Social Sciences, 7(5), 877-881.

Næss, P. (2009). Residential self-selection and appropriate control variables in land use: Travel studies. Transport Reviews, 29(3), 293-324.

NUCA (2016). New urban communities authority. Available online at http://www.newcities.gov.eg/english/ aboutUs/About Authority/default.aspx

Pagliara, F., Preston, J., Kim, J.-H. (2002). Residential location choice behaviour in Oxfordshire. TSU: REF, 925. Available online at https://trid.trb.org/view/683270.

Poku-Boansi, M., \& Adarkwa, K. K. (2016). Determinants of residential location in the Adenta municipality, Ghana. GeoJournal, 81(5), 779-791.

Rust, K., \& Gavera, C. (2013). Housing finance in Africa: A review of some of Africa's housing finance markets. Johannesburg: Center for Affordable Housing Finance in Africa.

Scheiner, J. (2014). Residential self-selection in travel behavior. Towards an integration into mobility biographies. Journal of Transport and Land Use, 7(3), 15-29.

Schwanen, T., \& Mokhtarian, P. L. (2004). The extent and determinants of dissonance between actual and preferred residential neighborhood type. Environment and Planning. B, Planning \& Design, 31(5), 759784.

Sener, I. N., Pendyala, R. M., \& Bhat, C. R. (2011). Accommodating spatial correlation across choice alternatives in discrete choice models: An application to modeling residential location choice behavior. Journal of Transport Geography, 19(2), 294-303.

Sims, D. (2012). Understanding Cairo: The logic of a city out of control Oxford University Press.

Sims, D. (2015). Egypt's desert dreams: Development or disaster? Oxford University Press.

Sims, D., Kamal, H., Solomon, D. (2008). Housing study for urban Egypt. USAID/EGYPT Policy and Private Sector Office, Technical Assistance for Policy Reform TAPRII.

Sinniah, G. K., Shah, M. Z., Vigar, G., \& Aditjandra, P. T. (2016). Residential location preferences: New perspective. Transportation Research Procedia, 17, 369-383. 
Ubani, P., Alaci, D. S.A, Udoo, V. (2017). Determinants of residential Neighbourhood choice in a Nigerian Metropolis. Available online at https://pdfs.semanticscholar.org/f5d5/ 1205c9365a3e12ca65a5431a03a2e95c1fa7.pdf.

UNICEF (2010). Child poverty and disparities in Egypt building the social infrastructure for Egypt's future (global study on child poverty and disparities). Cairo: United Nations Children's Fund (UNICEF).

Van der Vlist, A. J., Gorter, C., Nijkamp, P., \& Rietveld, P. (2002). Residential mobility and local housingmarket differences. Environment and Planning A, 34(7), 1147-1164.

Wang, D., \& Lin, T. (2014). Residential self-selection, built environment, and travel behavior in the Chinese context. Journal of Transport and Land Use, 7(3), 5.

Wang, M., Yang, Y., Jin, S., Gu, L., \& Zhang, H. (2016). Social and cultural factors that influence residential location choice of urban senior citizens in China - The case of Chengdu city. Habitat International, 53, 55-65.

World Bank (2008). A framework for housing policy reform in urban areas in Egypt. Developing a WellFunctioning Housing System and Strengthening the National Housing Program. Washington D.C. Available online at https://openknowledge.worldbank.org/handle/10986/7955

Yu, B., Zhang, J., \& Li, X. (2017). Dynamic life course analysis on residential location choice. Transportation Research Part A: Policy and Practice, 104, 281-292.

Zang, P., Lu, Y., Ma, J., Xie, B., Wang, R., \& Liu, Y. (2019). Disentangling residential self-selection from impacts of built environment characteristics on travel behaviors for older adults. Social Science \& Medicine (1982), 238, 112515.

Zondag, B., \& Pieters, M. (2005). Influence of accessibility on residential location choice. Transportation Research Record, 1902(1), 63-70.

Publisher's Note Springer Nature remains neutral with regard to jurisdictional claims in published maps and institutional affiliations.

\section{Affiliations}

\section{Houshmand Masoumi ${ }^{1,2}$. Mohamed R. Ibrahim ${ }^{3}$ - Atif Bilal Aslam ${ }^{4}$}

1 Center for Technology and Society, Technische Universität Berlin, Berlin, Germany

2 Department of Transport and Supply Chain Management, University of Johannesburg, Johannesburg, South Africa

3 SpaceTimeLab, Department of Civil, Environmental and Geomatic Engineering, University College London (UCL), London, UK

4 Department of City and Regional Planning, University of Engineering and Technology, Lahore, Pakistan 